\title{
BMJ Open Burden of herpes zoster in 16 selected immunocompromised populations in England: a cohort study in the Clinical Practice Research Datalink 2000-2012
}

\begin{tabular}{l}
\hline Emad A. Yanni, ${ }^{1}$ Germano Ferreira, ${ }^{2}$ Morgane Guennec, ${ }^{3}$ Yassine El Hahi, \\
Amale El Ghachi, ${ }^{5}$ François Haguinet, ${ }^{6}$ Emmanuelle Espie, ${ }^{6}$ Veronique Bianco ${ }^{1}$
\end{tabular}

To cite: Yanni EA., Ferreira G, Guennec M, et al. Burden of herpes zoster in 16 selected immunocompromised populations in England: a cohort study in the Clinical Practice Research Datalink 2000-2012. BMJ Open 2018;8:e020528. doi:10.1136/ bmjopen-2017-020528

- Prepublication history and additional material for this paper are available online. To view these files, please visit the journal online (http://dx.doi org/10.1136/bmjopen-2017020528).

Received 13 November 2017 Revised 23 February 2018 Accepted 30 April 2018

Check for updates

${ }^{1}$ GSK, Rockville, Maryland, USA ${ }^{2} \mathrm{P}-95$ Epidemiology and Pharmacovigilance Services, Heverlee, Belgium

${ }^{3}$ Keyrus Biopharma c/o GSK, Wavre, Belgium

${ }^{4}$ Valesta c/0 GSK, Wavre,

Belgium

${ }^{5}$ AIXIAL c/o GSK, Boulogne-

Billancourt, France

${ }^{6}$ GSK, Wavre, Belgium

Correspondence to

Dr Emad A. Yanni;

emad.a.yanni@gsk.com

\section{ABSTRACT}

Objectives Herpes zoster ( $\mathrm{HZ}$ ) is caused by reactivation of varicella-zoster virus which remains latent in individuals after a varicella infection. It is expected that $\mathrm{HZ}$ will be more frequent in immunocompromised (IC) individuals than in immunocompetent (IC-free). This study assessed the incidence rate $(\mathrm{IR})$ of $\mathrm{HZ}$ in individuals with a wide set of IC conditions and in IC-free individuals.

Setting A retrospective cohort study was conducted in England using data (January 2000 to March 2012) from the Clinical Practice Research Datalink with linkage to the Hospital Episodes Statistics.

Participants A cohort of 621588 individuals with 16 selected IC conditions and a gender/age-matched cohort of IC-free individuals were identified. The IC conditions included haematopoietic stem cell transplant (HSCT), solid organ transplant, malignancies, autoimmune diseases and users of immunosuppressive medications.

Outcomes IR of HZ per 1000 person-years (PY) was estimated. Proportions of postherpetic neuralgia (PHN) and other $\mathrm{HZ}$ complications within 90 days of $\mathrm{HZ}$ onset were also estimated among patients with $\mathrm{HZ}$. Risk factors for PHN in IC individuals with $\mathrm{HZ}$ were assessed by a multivariate regression model.

Results The overall IR of $\mathrm{HZ}$ in the IC cohort was 7.8/1000 PY $(95 \% \mathrm{Cl} 7.7$ to 7.9$)$, increasing with age from $3.5 / 1000$ PY (3.4-3.7) in individuals aged $18-49$ years to $12.6 / 1000$ PY (12.2-13.0) in individuals aged $\geq 80$ years. This IR in the IC-free cohort was 6.2/1000 PY (6.1-6.3). The overall IR of $\mathrm{HZ}$ varied across IC conditions, ranging from 5.3 (5.1-5.5) in psoriasis to $41.7 / 1000$ PY (35.7-48.4) in HSCT. The proportions of $\mathrm{PHN}$ and other $\mathrm{HZ}$ complications were $10.7 \%(10.2-11.1)$ and $2.9 \%(2.7-3.2)$ in the IC cohort, but $9.1 \%(8.7-9.5)$ and $2.3 \%(2.1-2.6)$ in the IC-free cohort, respectively.

Conclusion IC population contributes to the public health burden of $\mathrm{HZ}$ in England. Vaccination might be the most preferable $\mathrm{HZ}$ preventive measure for the IC population.

\section{INTRODUCTION}

Herpes zoster (HZ) is usually a painful vesicular skin rash occurring more frequently in older adults and immunocompromised (IC) individuals. $\mathrm{HZ}$ is caused by reactivation of

\section{Strengths and limitations of this study}

- A retrospective cohort study based on the Clinical Practice Research Datalink (CPRD) to estimate the incidence of herpes zoster in individuals with the most common immunocompromised conditions in England.

- The CPRD includes continuous patients' records for about $7 \%$ of the UK population and is broadly representative of the characteristics of patients and general practitioner practices in the UK, with long follow-up and quality data.

- Sixty per cent of patients in the CPRD have data available in the Hospital Episode Statistics database and we used these linked data.

- A matched cohort of immunocompetent individuals was included, with 1:1 matching based on year of birth, gender and practice geographical location.

- The individuals with none of the selected immunocompromised conditions diagnosed are not necessarily immunocompetent.

the latent varicella-zoster virus (VZV) when VZV specific cell-mediated immunity (CMI) declines. ${ }^{12}$

A variety of $\mathrm{HZ}$ risk factors including immunocompromising conditions (eg, solid organ and haematological malignancies, haematopoietic stem cell and solid organ transplant), immunosuppressive drugs, chronic medical conditions (eg, diabetes and chronic obstructive pulmonary disease (COPD)) and advancing age may negatively interfere with VZV-specific CMI. ${ }^{3-5}$

Despite contributing a small fraction of overall HZ cases, individuals with IC conditions make a large contribution to the societal healthcare burden because of their higher risk for $\mathrm{HZ}$ and $\mathrm{HZ}$ complications, including $\mathrm{HZ}$ ophthalmicus and postherpetic neuralgia (PHN), that may require patient hospitalisation and/or changes of the treatment 
regimen. ${ }^{346-9}$ IC patients with $\mathrm{HZ}$ are also more likely to develop recurrent $\mathrm{HZ}$ episodes. ${ }^{10}$

While there are few studies providing an estimate of the incidence of $\mathrm{HZ}$ in a set of selected IC conditions or patients with altered immune function, ${ }^{34}$ many studies have assessed the risk of developing HZ in specific individual IC conditions, such as cancers, ${ }^{5} 1112$ rheumatoid arthritis (RA) ${ }^{13}$ psoriasis (PSOR) ${ }^{14-16}$ and inflammatory bowel diseases (IBD) ${ }^{17}$ Currently, there is no study evaluating the full burden of $\mathrm{HZ}$ in a wider IC population, including $\mathrm{HZ}$ complications, healthcare resource utilisation and associated costs.

This study therefore aimed to estimate the incidence of $\mathrm{HZ}$ in a selected IC population and in an IC-free (ie, immunocompetent) population aged $\geq 18$ years. Among patients with HZ, the proportions of PHN and other HZ-related complications, recurrence and HZ-associated mortality rates were assessed. We also investigated risk factors for developing PHN among patients with $\mathrm{HZ}$ in the selected IC population.

\section{METHODS}

This was a retrospective observational cohort study using data from the UK Clinical Practice Research Datalink (CPRD). This is a primary care database of almost 12 million anonymised patient medical records including clinical events (medical diagnoses), referrals to specialists and secondary care, diagnostics tests, medical prescriptions, other routine medical services provided in general practices and some lifestyle factors (ie, smoking and alcohol consumption). ${ }^{18}$ The information in CPRD is coded with Read codes, which contain hundreds of thousands of clinical terms, synonyms and abbreviations covering all aspects of patient care including signs and symptoms, treatment and therapies, investigations, occupations, diagnoses and drugs. ${ }^{19}$

CPRD currently contains records for about 4.4 million individuals ( $7 \%$ of the UK population) registered with 674 general practitioner (GP) practices $^{20}$ and is considered to be broadly representative of the characteristics of patients and GP practices in the UK. ${ }^{18} 2021$ Fifty-eight per cent of the CPRD practices (a subset of English practices) are linked to the Hospital Episode Statistics (HES) database storing International Classification of Diseases (ICD) codes from hospital attendances (admissions and outpatient visits) and to the Office for National Statistics mortality data including dates and causes of deaths. ${ }^{20}$

\section{Study cohorts}

The study population consisted of active individuals aged $\geq 18$ years recorded in CPRD with HES linkage any time between 1 January 2000 and 31 March 2012, and with at least 1 year of follow-up in CPRD before the study inclusion.

An IC cohort was selected including all eligible individuals with at least one of the following IC conditions or therapies: haematopoietic stem cell transplant (HSCT); solid organ transplantation (SOT); solid organ malignancy (SOM); haematological malignancy (HM); HIV; end-stage renal disease (ESRD); corticosteroids exposure (CORTDS); other immunosuppressive therapy (OIT) exposures including biological treatments; other immunodeficiency conditions (OIC); and autoimmune diseases (AID). The AIDs comprised: RA, systemic lupus erythematosus (SLE), IBDs, PSOR, multiple sclerosis (MS), polymyalgia rheumatica and autoimmune thyroiditis (AT). Individuals could be included in more than one IC condition except in the event of CORTDS or OIT exposures, where no concurrent IC condition was permitted (see online supplementary material for further details on IC conditions case definition).

An index date for each IC individual was defined as the earliest date of diagnosis of the IC condition/medical procedure or the date of the earliest prescription of corticosteroids or OIT. The earliest index date possible was 1 January 2000.

An IC-free cohort was randomly selected from the study population of eligible individuals, who were not included in the IC cohort. IC-free individuals were matched 1:1 to IC individuals by year of birth, gender and geographical region of the GP practice. IC-free individuals were assigned the same index date as their matched IC individuals. The matched IC and IC-free cohorts were followed up from the index date until the earliest of the following events: transfer out of the practice date, the last GP practice collections date, death date or the end of the study (31 March 2012).

In order to ensure that $\mathrm{HZ}$ cases were new events, a period of at least 12 months of registration in CPRD was required before the inclusion of study population in the study. Individuals with a history of HZ or related complications identified within at least 12 months before the index date of IC condition (for the IC cohort) or the date of inclusion in the study (for the IC-free cohort) were excluded.

\section{Endpoints related to $\mathrm{HZ}$ diagnoses}

Incident $\mathrm{HZ}$ was identified as the first reported diagnosis of HZ by using ICD10 codes (B02, B02.0, B02.1, B02.3, B02.30-34, B02.39, B02.7, B02.8, B02.9) in HES or corresponding Read codes in CPRD (online supplementary table SM1). PHN was defined by using ICD10 codes (B02.2, B02.21-24, B02.29) in HES or Read codes (A531.11, A531200, A531300, A531500, A531511, F300.00) in CPRD, within 90 days of the incident HZ. HZ-related complications including neurological (other than PHN), ocular and disseminated were considered as $\mathrm{HZ}$ complications if they were coded as $\mathrm{HZ}$ complications (subhierarchy of ICD10 code B02 or corresponding Read codes) and if diagnosed within 90 days of the incident HZ (online supplementary table SM1). Potential associated vascular complications (such as stroke, transient ischaemic attack, optic neuritis and vascular retinitis, and myocardial infarction) were also identified (online supplementary table SM2). 
A recurrent $\mathrm{HZ}$ episode was defined as any $\mathrm{HZ}$ episode occurring after a 180-day disease-free period of $\mathrm{HZ}$ or HZ complications (except PHN).

\section{Statistical analyses}

The incidence rate (IR, with 95\% CI) of HZ per 1000 person-years (PY) was calculated as the total number of incident $\mathrm{HZ}$ cases divided by the sum of the number of $\mathrm{PY}$ at risk. The risk period for IC individuals was defined from the index date of the IC condition until the earliest of the following events: first reported HZ episode, end of IC drugs exposure (90 days for CORTDS and 180 days for OIT after the last prescription), date of death, transfer out of a GP practice contributing to CPRD, the last GP practice collections date or end of the study (31 March 2012). The IR was estimated by age strata, gender and by type of IC condition for the IC cohort.

The proportions of PHN and HZ complications other than PHN were calculated as the percentage of patients with $\mathrm{HZ}$ who developed PHN or at least one other HZ complication, respectively. The proportions were estimated overall and stratified by age group, gender and type of IC condition for the IC cohort.

The proportion of recurrent HZ was calculated as the proportion of patients with $\mathrm{HZ}$ with at least one recurrent $\mathrm{HZ}$ event within 24 months of the incident HZ. The mortality associated with HZ per 1 million PY was estimated as the total number of deaths attributable to $\mathrm{HZ}$ (ie, primary cause or contributory cause of death) divided by the number of PY at risk.
As PHN is the most frequently reported HZ complication, a logistic regression model was developed for IC individuals with $\mathrm{HZ}$ to identify the potential risk factors associated with the development of PHN. Factors such as age, gender, body mass index, smoking and alcohol consumption status and comorbidities (ie, COPD, depression, diabetes mellitus and asthma) were included in the model. A backward selection was conducted and the ORs with Wald 95\% CIs were estimated.

\section{Patient and public involvement}

No patients were involved in setting the research question or the outcome measures, nor were they involved in the design and implementation of the study. There are no plans to involve patients in the dissemination of results.

\section{RESULTS}

The study population included 3698346 individuals aged $\geq 18$ years that met the inclusion criteria (online supplementary table SM3). Among them, 621588 individuals were included in the IC cohort. The mean age of the IC individuals was 56.2 years, $56.1 \%$ were women, and the mean follow-up duration from the index date until the end of follow-up in the study was 5.1 years (table 1 ).

\section{Incidence of $\mathrm{HZ}$}

The overall IR of HZ in the IC cohort was $7.77 / 1000$ PY (95\% CI 7.67 to 7.88 ) and in the IC-free cohort $6.21 / 1000$ PY $(95 \%$ CI 6.12 to 6.30$)$. In the IC cohort, the overall
Table 1 Demographic characteristics of matched IC and IC-free cohorts, HES-CPRD, 2000-2012

\begin{tabular}{|c|c|c|c|}
\hline \multirow[b]{2}{*}{ Characteristics } & \multirow[b]{2}{*}{ Parameters or categories } & \multirow{2}{*}{$\begin{array}{l}\text { IC cohort } \\
\mathrm{N}=621588 \\
\text { Value or } \mathrm{n}(\%)\end{array}$} & \multirow{2}{*}{$\begin{array}{l}\text { IC-free cohort } \\
\mathrm{N}=621588 \\
\text { Value or } \mathrm{n}(\%)\end{array}$} \\
\hline & & & \\
\hline Gender & Female & $348752(56.11)$ & $348752(56.11)$ \\
\hline \multirow[t]{2}{*}{ Age (years) at index date } & Mean & 56.2 & 56.2 \\
\hline & IQR & 29.0 & 29.0 \\
\hline \multirow[t]{3}{*}{ Age group (years) at index date } & $18-49$ & 223400 (35.94) & $223400(35.94)$ \\
\hline & $50-59$ & $107003(17.21)$ & $107003(17.21)$ \\
\hline & $60-64$ & $61390(9.88)$ & $61390(9.88)$ \\
\hline \multirow{4}{*}{$\begin{array}{l}\text { Follow-up period from index date to the end } \\
\text { of follow-up in the study (years) }\end{array}$} & Mean & 5.1 & 4.9 \\
\hline & SD & 3.9 & 3.8 \\
\hline & Median & 4.3 & 4.1 \\
\hline & IQR & 6.7 & 6.2 \\
\hline
\end{tabular}

\%, 100*n/N; CPRD, Clinical Practice Research Datalink; HES, Hospital Episode Statistics; IC, immunocompromised; N, total number of individuals; $\mathrm{n}$, number of individuals in the specified category. 
IR of HZ increased with age from 3.55/1000 PY (95\% CI 3.42 to 3.68 ) in persons aged $18-49$ years to $12.22 / 1000$ PY (95\% CI 12.22 to 13.02$)$ in persons aged $\geq 80$ years (table 2).

In this cohort, the age-specific IRs of HZ remained almost constant throughout the study period with no discernible trend for any age group (figure 1). The overall IR of HZ in IC women was 8.48/1000 PY (8.348.63), compared with $6.83 / 1000$ PY (6.68-6.98) in IC men (figure 2).

For the selected IC conditions, the overall IRs of HZ ranged from 5.33/1000 PY (5.15-5.51) for PSOR to 41.70/1000 PY (35.72-48.40) for HSCT (table 2). For other IC conditions, the IRs of HZ were 15.19/1000 PY for HM, 12.25/1000 PY for ESRD, 12.13/1000 PY for SOT, $11.83 / 1000$ PY for OIC, $11.78 / 1000$ PY for HIV and 6.98/1000 PY for all AIDs combined. The IRs of HZ for most of IC conditions rose steadily with increasing age except for HSCT, HM, ESRD, SLE and MS (table 2).

\section{Proportion of PHN}

The proportion of PHN among patients with HZ in the IC cohort was $10.65 \%$ (10.24-11.08) within 90 days of the incident HZ (table 3 ). This proportion increased steeply with age from $3.21 \%(2.62-3.90)$ in patients aged 18-49 years to $15.05 \%(13.94-16.22)$ in patients aged $\geq 80$ years (online supplementary table SM4). The proportion of PHN was 9.09\% (8.68-9.52) in the IC-free cohort. Across the IC conditions, the proportion of PHN ranged from 8.33\% (3.67-15.76) in HIV-infected patients to $15.61 \%$ (10.54-21.89) in patients with HSCT (online supplementary table SM5).

\section{Proportion of HZ-related complications other than PHN}

Within 90 days of the incident HZ, 2.95\% (2.72-3.18) of IC patients reported at least one HZ complication other than PHN, compared with $2.35 \%(2.13-2.57)$ of the IC-free patients (table 3). Ocular complications were the most frequently reported complications in both cohorts. Across the IC conditions, the proportion of patients with at least one $\mathrm{HZ}$ complication other than PHN ranged from $1.81 \%$ in patients with OIT to $6.94 \%$ in patients with HSCT (online supplementary table SM5). The proportions of IC patients with at least one HZ-associated vascular complication within 90 days of $\mathrm{HZ}$ onset were the following: $0.42 \%$ for stroke, $0.25 \%$ for transient ischaemic attack, $0.17 \%$ for myocardial infarction and $0.04 \%$ for optic neuritis/vascular retinitis (table 3 ).

\section{Recurrence of $\mathrm{HZ}$ and $\mathrm{HZ}$-associated mortality}

$\mathrm{HZ}$ recurrence within 2 years of the incident $\mathrm{HZ}$ was $2.26 \%(2.01-2.52)$ in the IC cohort and $1.54 \%$ (1.33$1.77)$ in the IC-free cohort. The HZ-associated mortality rate was 7.42/1 $000000 \mathrm{PY}(4.53-11.47)$ in the IC cohort and 3.72/1 000000 PY (1.86-6.65) in the IC-free cohort.

\section{Risk factors for developing PHN among IC patients with $\mathrm{HZ}$}

After adjusting for covariates, increasing age (eg, $\geq 80$ years vs $18-44$ years, adjusted OR (AOR): 7.02; 5.22-9.43), current (AOR: 1.35; 1.07-1.69) and ex-drinkers (AOR: $1.60 ; 1.02-2.49$ ), depression (AOR: $1.31 ; 1.10-1.52$ ) and COPD (AOR: $1.28 ; 1.12-1.46$ ) were associated with increased risk of PHN (online supplementary table SM6).

\section{DISCUSSION}

To our knowledge, this study is the largest study to date investigating the incidence of $\mathrm{HZ}$ in $\geq 18$-year-old adults in the UK with a wide variety of IC conditions, including exposure to immunosuppressive therapies. It showed a high burden of $\mathrm{HZ}$ among individuals with the selected IC conditions, overall and across different age groups. With the exception of PSOR, MS and AT, the IRs of HZ for all the selected IC conditions were above the estimated overall IR in the IC-free cohort, with differences rising up to sevenfold as in patients with HSCT.

For some IC conditions, these findings are consistent with what was observed in other studies focusing on HSCT, ${ }^{3}$ RA, ${ }^{322-25}$ IBD $^{4}$ and SLE. ${ }^{326}{ }^{27}$ For other IC conditions, the estimated IRs were slightly lower than those reported in the literature: PSOR, ${ }^{31415} \mathrm{IBD},{ }^{317} \mathrm{MS},{ }^{3}$ $\mathrm{SOM}^{511}$ and HM. ${ }^{511}$ However, this study showed the same ratio between HM and SOM as those previously reported, with incidence of $\mathrm{HZ}$ twofold higher in $\mathrm{HM}$ than in SOM. ${ }^{511}$ The observed differences between our findings and the other studies may be due to varying case definitions, study designs, age distributions of the study populations and use of different immunosuppressive treatments or regimens.

Regarding exposures to corticosteroids and immunosuppressive therapies, the study showed incidences of $\mathrm{HZ}$ similar to the overall incidence among IC individuals. As no study has evaluated the burden of $\mathrm{HZ}$ in a population only defined by the use of immunosuppressive drugs outside the context of a specific IC condition, these findings could not be put in perspective. However, they are similar to the findings of other studies such as a meta-analysis showing a higher risk of $\mathrm{HZ}$ for individuals using biologics, non-biological disease-modifying antirheumatic drugs or corticosteroids for $\mathrm{AIDs}^{28}$ and studies describing an increased risk of HZ among patients with cancer who initiated treatment with immunosuppressants or chemotherapy. ${ }^{3511}$

Consistent with studies conducted in the UK and Germany, the IRs of HZ in the IC cohort increased steadily with age. ${ }^{49}$ However, regardless of the age group, the age-specific IRs of $\mathrm{HZ}$ in the IC cohort were almost constant throughout the study period 2000-2011.

The overall proportion of PHN in the IC cohort was $10.65 \%$ within 90 days of incident HZ; ranging from $8.43 \%$ in patients with OIT, AT, MS, HIV and SOT to $15.61 \%$ in patients with HSCT. These results are comparable to the findings of Forbes $e t$ al, except for the HSCT $(\mathrm{PHN}=29.4 \%) .{ }^{30}$ On the other hand, a study conducted by Habel et alshows a lower proportion of PHN in patients with $\mathrm{HM}(5.7 \%)$ and SM (8.6\%) within 90 days of $\mathrm{HZ}$ incident compared with their rates in this study. ${ }^{11}$ 


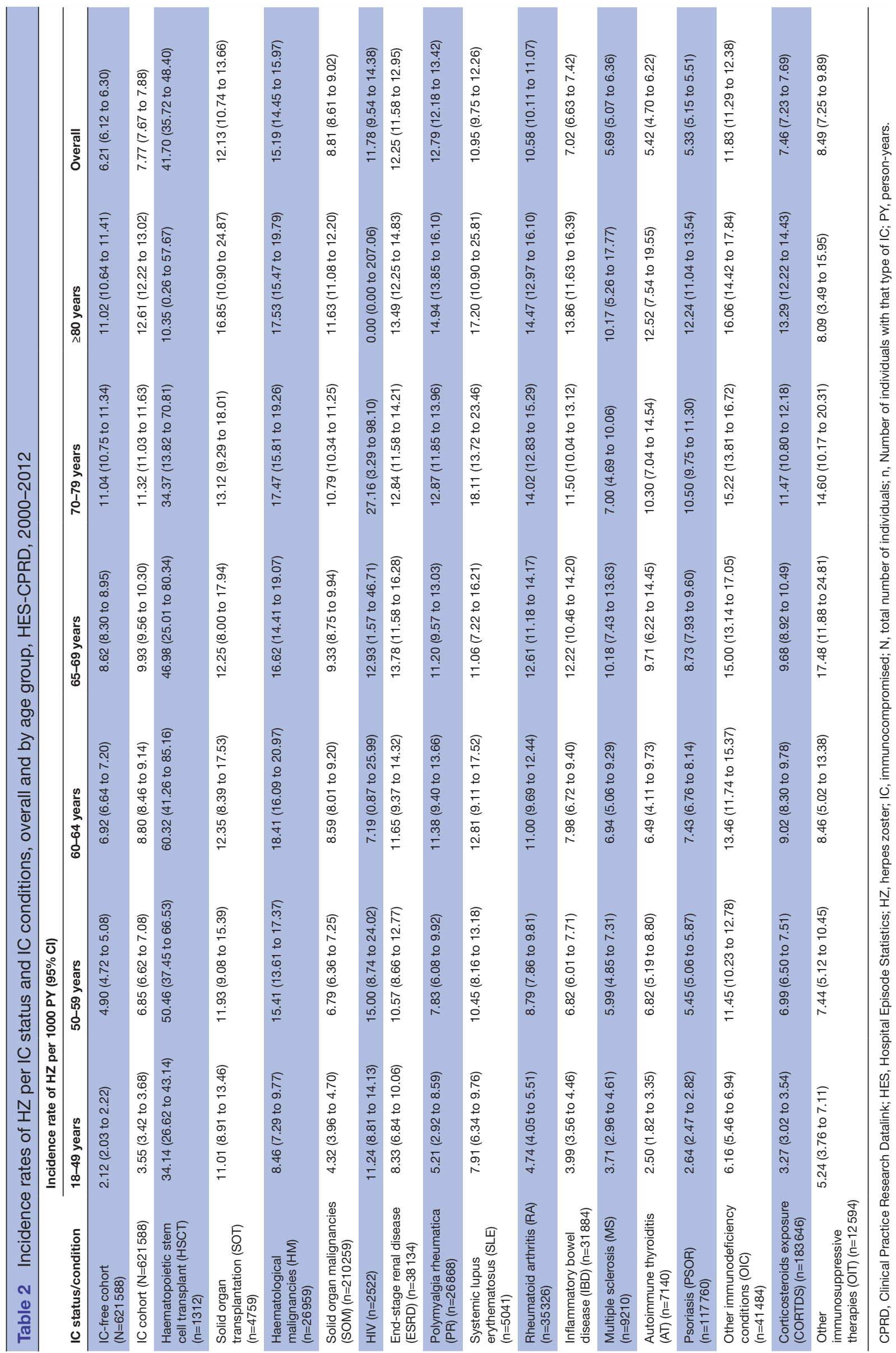




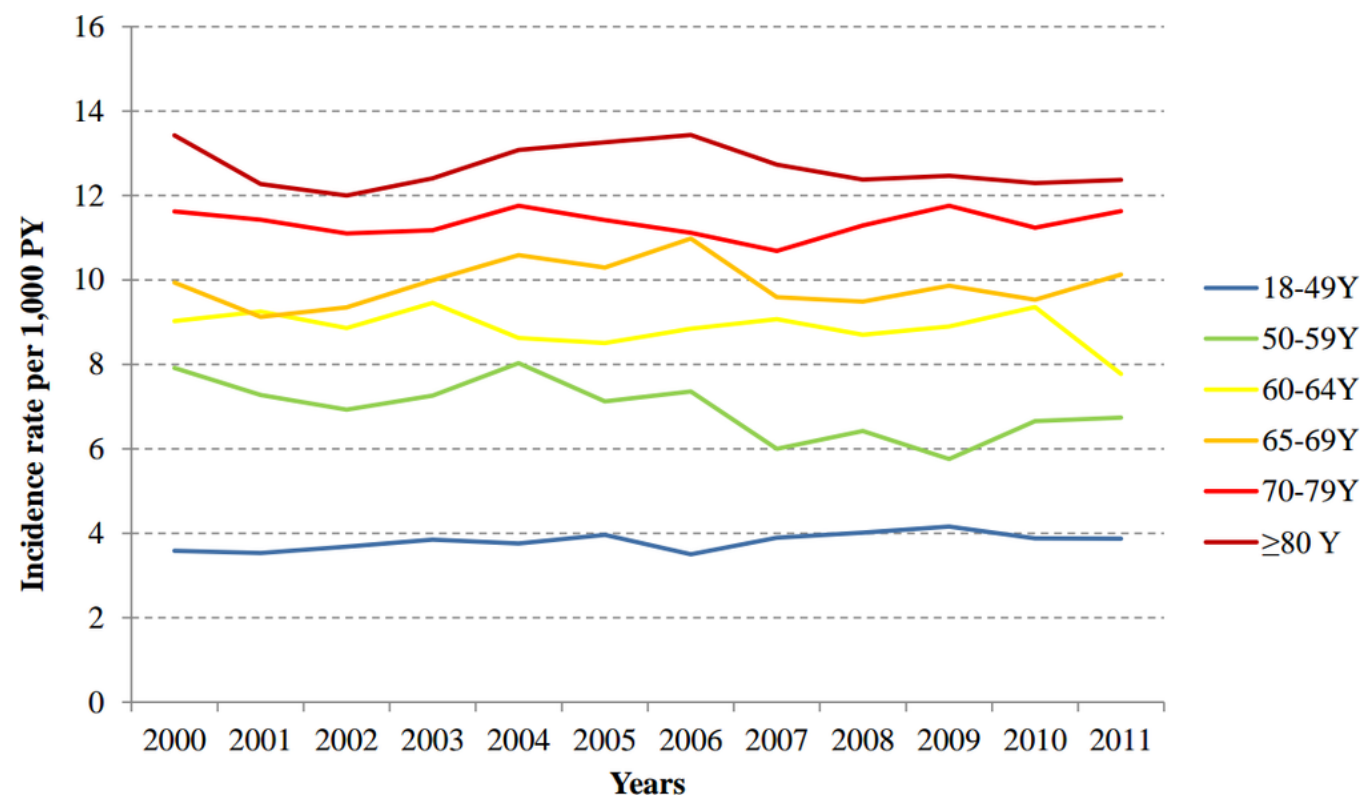

Figure 1 Age-specific yearly IRs of $\mathrm{HZ}$ in the IC cohort over the study period 2000-2012 (HES-CPRD). CPRD, Clinical Practice Research Datalink; HES, Hospital Episode Statistics; HZ, herpes zoster; IC, immunocompromised; IR, incidence rate; PY, person-years; $\mathrm{Y}$, years old.

These differences may be explained by varying definitions of PHN used, different study designs and age distributions of the study populations. ${ }^{6}$ Here, PHN was identified based on diagnosis codes whereas other studies used algorithms combining PHN diagnosis codes and/ or pain medication prescriptions. ${ }^{29-31}$ The conservative approach used here may have led to an underestimation of PHN in certain IC populations. We used an equally conservative approach to identify HZ-related complications other than PHN. By using only the diagnosis codes mentioning HZ-related complications, the estimated overall proportion of around 3\% (not including vascular complications) is probably an underestimate.

Furthermore, we estimated the proportion of patients with at least one of these non-PHN complications and not the frequency of each type separately, so patients with $\mathrm{HZ}$ with more than one complication were only counted once in the totals. Our results are nevertheless consistent with the literature and suggest that patients with $\mathrm{HZ}$ with IC conditions experience an age-related increase in the proportion developing non-PHN complications similar to what is observed in the general population. ${ }^{4}$

There is increasing evidence from general population studies establishing $\mathrm{HZ}$ as a risk factor for stroke and other vascular complications, particularly during the 3 months following HZ onset. ${ }^{32-34}$ No previous study has reported on the frequency of vascular complications in IC individuals with $\mathrm{HZ}$ infection. We estimated an overall proportion with at least one vascular complication of around $0.9 \%$ in the IC cohort of patients with HZ but this cannot be compared with the general population studies.

Additional analyses were performed to evaluate the proportions of HZ-related complications, including PHN, occurring within 365 days of incident HZ (data not shown). However, no difference was observed in the proportion of HZ complications reported within 90 and 365 days of incident HZ. This confirms the findings of Yawn $e t$ al that the majority of HZ-related complications occur within a short time ( 3 months) of rash onset. ${ }^{35}$

The proportion of patients with $\mathrm{HZ}$ experiencing $\mathrm{HZ}$ recurrence within 2 years of an $\mathrm{HZ}$ episode estimated in this study was lower than those reported in the literature, ${ }^{10}$ but higher than those observed in the IC-free cohort or in an immunocompetent US population. ${ }^{10}$ These differences might be explained by varying study population characteristics (ie, age distribution, underlying conditions and severity of immunosuppression).

There are few data available on HZ-related mortality and these are only for the general population. ${ }^{6}{ }^{36}$ The reported HZ-associated mortality incidence in the adult general population ranges from 0.94 to $2.86 / 1000000$ $\mathrm{PY}^{37-39}$ which is lower than what was observed in the IC-free cohort in this study.

Among the IC patients with $\mathrm{HZ}$, we found that increasing age is strongly associated with increasing risk of PHN. Other risk factors including COPD, depression and alcohol consumption have lower effect as risk factors of PHN. ${ }^{30}$ A previous study conducted in the general population of the UK has already established advancing age, severe immunosuppression and autoimmune conditions as PHN risk factors ${ }^{40}$; confirming our findings. Other clinical features of acute HZ (such as prodromal pain and increased rash severity) have also been accepted as risk factors for PHN ${ }^{40-42}$ However, such data were not available in CPRD so these potential risk factors could not be assessed in this study.

The IC cohort in this study represented $16.8 \%$ of the study population; which was higher than their estimate in other studies. ${ }^{43}$ This might be due to the large number of IC conditions that were followed up during the study 
A

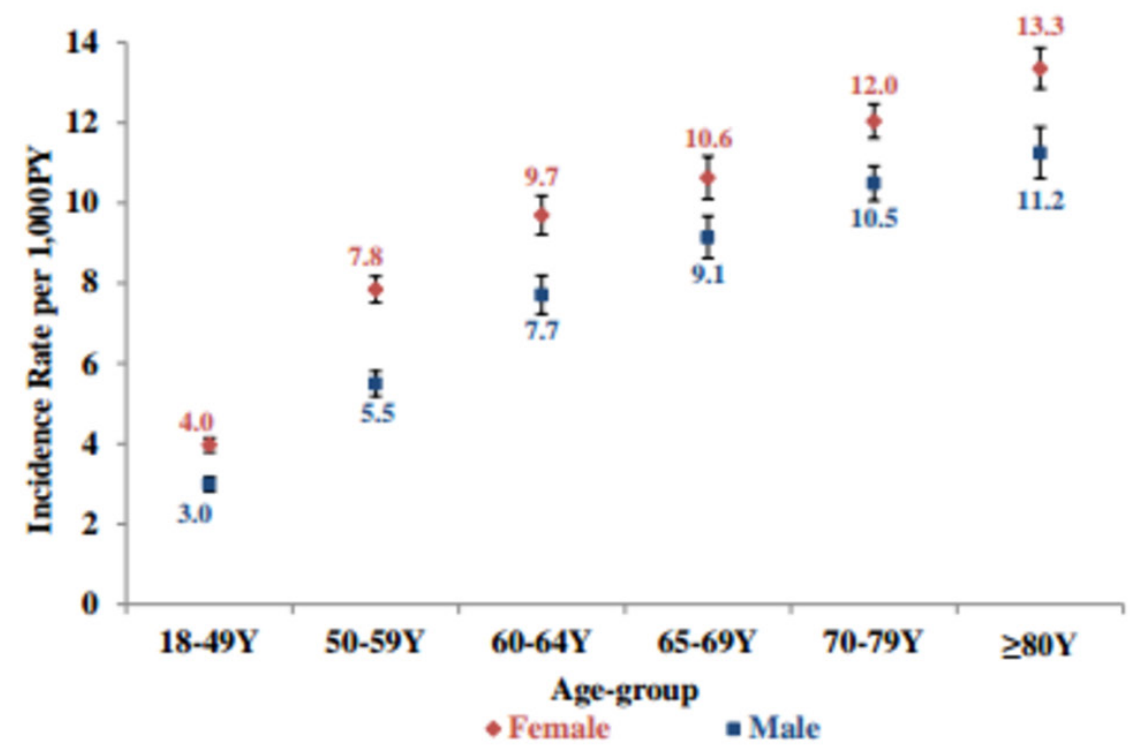

B

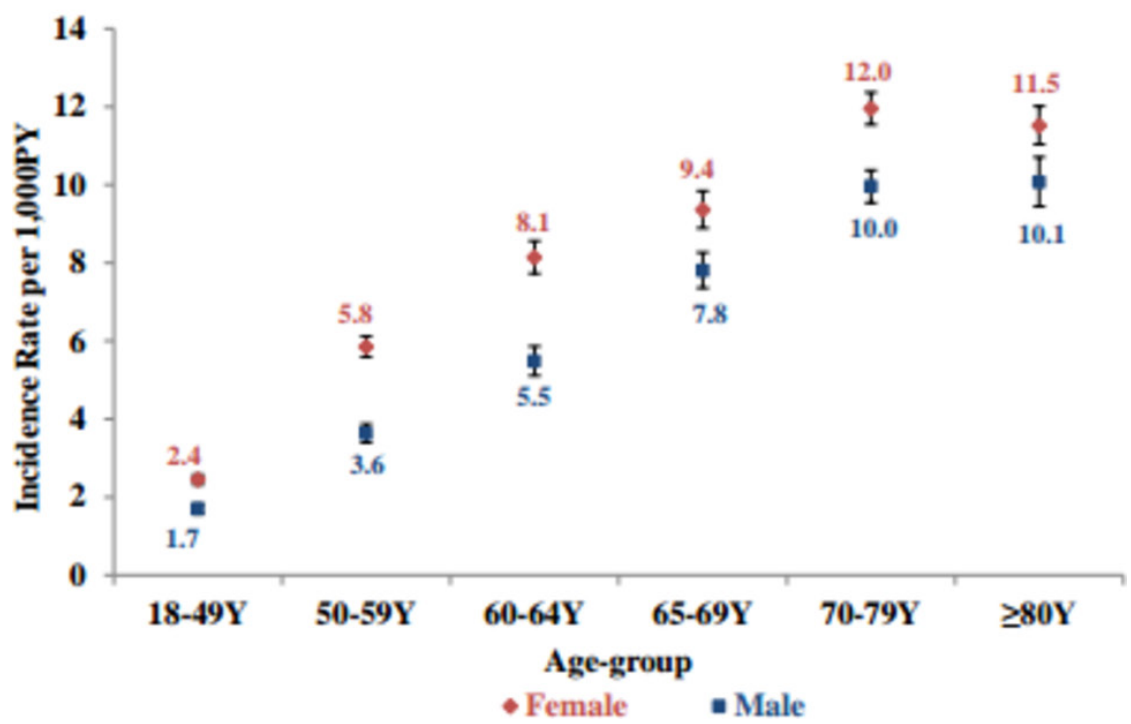

Figure 2 Incidence rates of HZ per $1000 \mathrm{PY}$ in both IC (A) and IC-free cohorts (B) by age group and gender, HESCPRD, 2000-2012. CPRD, Clinical Practice Research Datalink; HES, Hospital Episode Statistics; HZ, herpes zoster; IC, immunocompromised; PY, person-years; Y, years old.

period. Our study results indicate that this IC population bears a disproportionate part of the burden of $\mathrm{HZ}$ and its complications in England.

The main strength of this study was the use of a large medical records database considered to be broadly representative of the UK population. ${ }^{20}$ The linkage with HES data is only available for participants in England, but it has been reported that there are no substantial differences in participant characteristics between those that are linked to HES and those that are not. ${ }^{44}$ Therefore, over a $12+$ year study period, the use of CPRD with HES linkage allowed accurate and powerful estimation of HZ IRs.
In addition, the incidence of HZ in the IC-free cohort was slightly higher than the incidence of $\mathrm{HZ}$ observed in the UK general population (including both immunocompetent and IC people)..$^{314546}$

However, due to the varying quality and completeness over patients and time of this primary care database, ${ }^{20}$ a misclassification of individuals into the IC or IC-free cohorts may have occurred, as the classification was based on the coding practices and depended on the reliability of the GPs' data entry. ${ }^{47}$ Further research should explore the temporal relationship between the time of $\mathrm{HZ}$ incident and the level of severity of immunosuppression, in order 
Table 3 Proportion of patients with $\mathrm{HZ}$ with PHN, at least one $\mathrm{HZ}$ complication other than PHN, or vascular complications as assessed within 90 days of $\mathrm{HZ}$ onset, HES-CPRD, 2000-2011

\begin{tabular}{|c|c|c|c|c|}
\hline \multirow[b]{2}{*}{ Type of complications } & \multicolumn{2}{|c|}{ IC cohort $(\mathrm{N}=21146)$} & \multicolumn{2}{|c|}{ IC-free cohort $(\mathrm{N}=18583)$} \\
\hline & n (\%) & $95 \% \mathrm{Cl}$ & $\mathrm{n}(\%)$ & $95 \% \mathrm{Cl}$ \\
\hline PHN & $2253(10.65)$ & 10.24 to 11.08 & $1690(9.09)$ & 8.68 to 9.52 \\
\hline HZ complications other than PHN (overall) & $623(2.95)$ & 2.72 to 3.18 & $436(2.35)$ & 2.13 to 2.57 \\
\hline Ocular & $411(1.94)$ & 1.76 to 2.14 & $299(1.61)$ & 1.43 to 1.8 \\
\hline Neurological other than PHN & $137(0.65)$ & 0.54 to 0.77 & $85(0.46)$ & 0.37 to 0.57 \\
\hline Disseminated & $12(0.06)$ & 0.03 to 0.1 & $1(0.01)$ & 0 to 0.03 \\
\hline Other complications & $69(0.33)$ & 0.25 to 0.41 & $54(0.29)$ & 0.22 to 0.38 \\
\hline \multicolumn{5}{|l|}{ Vascular complications } \\
\hline Stroke & $88(0.42)$ & 0.33 to 0.51 & $105(0.57)$ & 0.46 to 0.68 \\
\hline Transient ischaemic attack & $52(0.25)$ & 0.18 to 0.32 & $30(0.16)$ & 0.11 to 0.23 \\
\hline Optic neuritis, vascular retinitis & $9(0.04)$ & 0.02 to 0.08 & $5(0.03)$ & 0.01 to 0.06 \\
\hline Myocardial infarction & $36(0.17)$ & 0.12 to 0.24 & $23(0.12)$ & 0.08 to 0.19 \\
\hline
\end{tabular}

CPRD, Clinical Practice Research Datalink; HES, Hospital Episode Statistics; HZ, herpes zoster; IC, immunocompromised; N, Number of patients with $\mathrm{HZ}$; $\mathrm{n}(\%)$, number (percentage) of the patients with $\mathrm{HZ}$ with this complication; PHN, postherpetic neuralgia.

to develop appropriate interventions to improve the quality of life of IC individuals. In addition, patients with chronic medical conditions might attend the GP practices more frequently than IC-free population. This may result in a potential information bias because of the increased likelihood that IC patients with any HZ-related symptoms will seek the GP medical advice more frequently than IC-free individuals.

The stable trend of age-specific IR of HZ in IC cohort throughout the study period (2000-2011) might show different pattern if we run the analysis in each IC condition. For instance, the development of new medical treatment regimens for certain IC conditions or the change of treatment guidelines might influence the course of IC disease and the risk of HZ.

Despite these limitations, the results of this study strengthen the evidence that immunodeficiency from any cause increases the risk of HZ. Individuals with IC conditions suffer a higher burden of $\mathrm{HZ}$ and related complications than IC-free or immunocompetent individuals. The existing treatments for $\mathrm{HZ}$ are not always effective, do not prevent the development of PHN and the outcomes are deemed unsatisfactory by the patients. ${ }^{48}$ Therefore, new strategies to prevent HZ in patients with severe immunosuppression, such as vaccination, are an increasing priority. ${ }^{49}$

\section{CONCLUDING REMARKS}

This study confirms that IC individuals contribute substantially and disproportionately to the public health burden of $\mathrm{HZ}$ in England because of their higher risk for $\mathrm{HZ}$ and HZ-related complications. Further research should explore HZ risk in relation to the severity of immunosuppression and other available clinical information, to develop appropriate interventions to improve the quality of life of IC individuals. The expected increase in lifespan of the general population including IC populations might lead to an increase in the burden of HZ, unless appropriate preventive measures such as vaccination are in place.

Acknowledgements The authors thank Emmanuel Aris, Lidia Oostvogels, Dominique Rosillon, Desmond Curran, Antonio Olivieri, Catherine Cohet, Corinne Willame, Sophie Caterina, Manjit Hunjan and Celine Jegou for their contribution to the study. They also thank the Business and Decision Life Sciences platform for editorial assistance and coordination, on behalf of GSK. Gregory Collet coordinated the manuscript development and editorial support. Niels Neymark, independent scientific writer on behalf of GSK, provided writing support.

Contributors VB, AEG, YEH, GF, MG, FH and EAY participated in the conception and design of the study. VB, AEG, YEH, GF, MG, FH and EAY participated in the collection or generation of the study data. VB, AEG, YEH, MG and EAY performed the study. VB, AEG, YEH, MG and FH contributed to the material. VB, AEG, YEH, GF, $M G, F H, E E$ and EAY were involved in the analysis or interpretation of the data. All named authors provided substantial intellectual and scientific input during the manuscript development, critically reviewing the content, revising the manuscript and giving final approval before submission. The work described was carried out in accordance with the ICMJE recommendations for conducting, reporting, editing and publishing scholarly work in medical journals.

Funding GlaxoSmithKline Biologicals was the funding source and was involved in all study (e-track number: 201615) activities and data analysis. GlaxoSmithKline Biologicals also funded all costs associated with the development and the publishing of the present manuscript. All authors had full access to the data and the corresponding author was responsible for the submission of the manuscript. Confirmed

Competing interests VB, FH, EE and EAY are employees of the GSK group of companies. AEG, YEH and MG have nothing to disclose. GF was employed by the GSK group of companies between 2012 and February 2015, during which the study was designed and implemented. Later, as an employee of P-95 Epidemiology and Pharmacovigilance, GF provided contracted consultancy services to the GSK group of companies for this and other GSK-sponsored studies. P-95 provides contracted services to the GSK group of companies beyond the scope of this study.

Patient consent Not required.

Ethics approval Approval was obtained from the Clinical Practice Research Datalink Independent Scientific Advisory Committee (14_222R).

Provenance and peer review Not commissioned; externally peer reviewed.

Data sharing statement All data used in this study are presented in the manuscript, references to the original material are provided. Please contact the corresponding author should you require any additional information. 
Open Access This is an Open Access article distributed in accordance with the Creative Commons Attribution Non Commercial (CC BY-NC 4.0) license, which permits others to distribute, remix, adapt, build upon this work non-commercially, and license their derivative works on different terms, provided the original work is properly cited and the use is non-commercial. See: http://creativecommons.org/ licenses/by-nc/4.0/

(c) Article author(s) (or their employer(s) unless otherwise stated in the text of the article) 2018. All rights reserved. No commercial use is permitted unless otherwise expressly granted.

\section{REFERENCES}

1. Arvin A. Aging, immunity, and the varicella-zoster virus. $N$ Engl J Med 2005;352:2266-7.

2. Cohen Jl. Herpes zoster. N Engl J Med Overseas Ed 2013;369:255-63.

3. Chen SY, Suaya JA, Li Q, et al. Incidence of herpes zoster in patients with altered immune function. Infection 2014;42:325-34.

4. Forbes HJ, Bhaskaran K, Thomas SL, et al. Quantification of risk factors for herpes zoster: population based case-control study. BMJ 2014;348:g2911.

5. Yenikomshian MA, Guignard AP, Haguinet F, et al. The epidemiology of herpes zoster and its complications in Medicare cancer patients. BMC Infect Dis 2015;15:106.

6. Kawai K, Gebremeskel BG, Acosta CJ. Systematic review of incidence and complications of herpes zoster: towards a global perspective. BMJ Open 2014;4:e004833

7. Johnson RW, Alvarez-Pasquin MJ, Bijl M, et al. Herpes zoster epidemiology, management, and disease and economic burden in Europe: a multidisciplinary perspective. Ther Adv Vaccines 2015;3:109-20.

8. De Broucker T, Mailles A, Chabrier S, et al. Acute varicella zoster encephalitis without evidence of primary vasculopathy in a caseseries of 20 patients. Clin Microbiol Infect 2012;18:808-19.

9. Schmidt SA, Kahlert J, Vestergaard M, et al. Hospital-based herpes zoster diagnoses in Denmark: rate, patient characteristics, and allcause mortality. BMC Infect Dis 2016;16:99.

10. Yawn BP, Wollan PC, Kurland MJ, et al. Herpes zoster recurrences more frequent than previously reported. Mayo Clin Proc 2011;86:88-93.

11. Habel LA, Ray GT, Silverberg MJ, et al. The epidemiology of herpes zoster in patients with newly diagnosed cancer. Cancer Epidemiol Biomarkers Prev 2013;22:82-90.

12. Hansson E, Forbes HJ, Langan SM, et al. Herpes zoster risk after 21 specific cancers: population-based case-control study. $\mathrm{Br} J$ Cancer 2017;116:1643-51.

13. Yun $\mathrm{H}$, Xie F, Delzell $\mathrm{E}$, et al. Risks of herpes zoster in patients with rheumatoid arthritis according to biologic disease-modifying therapy. Arthritis Care Res 2015;67:731-6.

14. Dreiher J, Kresch FS, Comaneshter D, et al. Risk of herpes zoster in patients with psoriasis treated with biologic drugs. J Eur Acad Dermatol Venereol 2012;26:1127-32.

15. Shalom G, Zisman D, Bitterman H, et al. Systemic therapy for psoriasis and the risk of herpes zoster: a 500000 person-year study. JAMA Dermatol 2015;151:533-8.

16. Zisman D, Bitterman $\mathrm{H}$, Shalom $\mathrm{G}$, et al. Psoriatic arthritis treatment and the risk of herpes zoster. Ann Rheum Dis 2016;75:131-5.

17. Long MD, Martin C, Sandler RS, et al. Increased risk of herpes zoste among 108604 patients with inflammatory bowel disease. Aliment Pharmacol Ther 2013;37:420-9.

18. Campbell J, Dedman DJ, Eaton SC, et al. Is the CPRD GOLD population comparable to the U.K. population? Pharmacoepidemiol Drug Saf 2013;22:280.

19. NHS Connecting for Health. Read codes. 2011 https://digital.nhs.uk/ article/1104/Read-Codes

20. Herrett E, Gallagher AM, Bhaskaran K, et al. Data resource profile: clinical practice research datalink (CPRD). Int J Epidemiol 2015;44:827-36.

21. Williams T, van Staa T, Puri S, et al. Recent advances in the utility and use of the general practice research database as an example of a UK primary care data resource. Ther Adv Drug Saf 2012;3:89-99.

22. McDonald JR, Zeringue AL, Caplan L, et al. Herpes zoster risk factors in a national cohort of veterans with rheumatoid arthritis. Clin Infect Dis 2009;48:1364-71.

23. Smitten AL, Choi HK, Hochberg MC, et al. The risk of herpes zoster in patients with rheumatoid arthritis in the United States and the United Kingdom. Arthritis Rheum 2007;57:1431-8.
24. Wolfe F, Michaud K, Chakravarty EF. Rates and predictors of herpes zoster in patients with rheumatoid arthritis and non-inflammatory musculoskeletal disorders. Rheumatology 2006; 45:1370-5

25. Veetil BM, Myasoedova E, Matteson EL, et al. Incidence and time trends of herpes zoster in rheumatoid arthritis: a population-based cohort study. Arthritis Care Res 2013;65:854-61.

26. Borba EF, Ribeiro AC, Martin P, et al. Incidence, risk factors, and outcome of Herpes zoster in systemic lupus erythematosus. J Clin Rheumatol 2010;16:119-22.

27. Kahl LE. Herpes zoster infections in systemic lupus erythematosus: risk factors and outcome. J Rheumatol 1994;21:84-6.

28. Marra F, Lo E, Kalashnikov V, et al. Risk of herpes zoster in individuals on biologics, disease-modifying antirheumatic drugs, and/or corticosteroids for autoimmune diseases: a systematic review and meta-analysis. Open Forum Infect Dis 2016;3:ofw205.

29. Schröder C, Enders D, Schink T, et al. Incidence of herpes zoster amongst adults varies by severity of immunosuppression. $J$ Infect 2017;75:207-15.

30. Forbes HJ, Bhaskaran K, Thomas SL, et al. Quantification of risk factors for postherpetic neuralgia in herpes zoster patients: a cohort study. Neurology 2016;87:94-102.

31. Gauthier A, Breuer J, Carrington D, et al. Epidemiology and cost of herpes zoster and post-herpetic neuralgia in the United Kingdom. Epidemiol Infect 2009;137:38-47.

32. Erskine $\mathrm{N}$, Tran $\mathrm{H}$, Levin L, et al. A systematic review and metaanalysis on herpes zoster and the risk of cardiac and cerebrovascular events. PLoS One 2017;12:e0181565.

33. Marra F, Ruckenstein J, Richardson K. A meta-analysis of stroke risk following herpes zoster infection. BMC Infect Dis 2017;17:198.

34. Yang SY, Li HX, Yi XH, et al. Risk of stroke in patients with herpes zoster: a systematic review and meta-analysis. J Stroke Cerebrovasc Dis 2017;26:301-7.

35. Yawn BP, Saddier P, Wollan PC, et al. A population-based study of the incidence and complication rates of herpes zoster before zoster vaccine introduction. Mayo Clin Proc 2007;82:1341-9.

36. Bricout $\mathrm{H}$, Haugh $\mathrm{M}$, Olatunde $\mathrm{O}$, et al. Herpes zoster-associated mortality in Europe: a systematic review. BMC Public Health 2015;15:466.

37. Brisson M, Edmunds WJ. Epidemiology of Varicella-Zoster Virus in England and Wales. J Med Virol 2003;70(Suppl 1):S9-14.

38. Gonzalez Chiappe S, Sarazin M, Turbelin C, et al. Herpes zoster: burden of disease in France. Vaccine 2010;28:7933-8.

39. Mahamud A, Marin M, Nickell SP, et al. Herpes zoster-related deaths in the United States: validity of death certificates and mortality rates, 1979-2007. Clin Infect Dis 2012;55:960-6.

40. Forbes HJ, Thomas SL, Smeeth L, et al. A systematic review and meta-analysis of risk factors for postherpetic neuralgia. Pain 2016;157:30-54.

41. Drolet M, Brisson M, Schmader K, et al. Predictors of postherpetic neuralgia among patients with herpes zoster: a prospective study. $J$ Pain 2010;11:1211-21.

42. Opstelten W, Zuithoff NP, van Essen GA, et al. Predicting postherpetic neuralgia in elderly primary care patients with herpes zoster: prospective prognostic study. Pain 2007;132(Suppl 1):S52-59.

43. Varghese L, Curran D, Bunge E, et al. Contraindication of live vaccines in immunocompromised patients: an estimate of the number of affected people in the USA and the UK. Public Health 2017;142:46-9.

44. Gallagher AM, Williams T, Leufkens HG, et al. The impact of the choice of data source in record linkage studies estimating mortality in venous thromboembolism. PLoS One 2016;11:e0148349.

45. Scott FT, Johnson RW, Leedham-Green M, et al. The burden of herpes zoster: a prospective population based study. Vaccine 2006;24:1308-14.

46. Pinchinat S, Cebrián-Cuenca AM, Bricout $\mathrm{H}$, et al. Similar herpes zoster incidence across Europe: results from a systematic literature review. BMC Infect Dis 2013;13:170.

47. Bhattarai N, Charlton J, Rudisill C, et al. Coding, recording and incidence of different forms of coronary heart disease in primary care. PLoS One 2012;7:e29776.

48. Gater A, Abetz-Webb L, Carroll S, et al. Burden of herpes zoster in the UK: findings from the zoster quality of life (ZQOL) study. BMC Infect Dis 2014;14:402.

49. CDC (Centers for Disease Control and Prevention). Prevention of herpes zoster: recommendations of the advisory committee on immunization practices (ACIP). CDC. 2008 https://www.cdc.gov/ $\mathrm{mmwr} /$ preview/mmwrhtml/rr57e0515a1.htm 